\title{
Epidemiological trends and risk factors associated with dengue disease in Pakistan (1980-2014): a systematic literature search and analysis
}

Jehangir Khan ${ }^{1,2,3,8^{*}}$ (D), Inamullah Khan ${ }^{4}$, Abdul Ghaffar ${ }^{5}$ and Bushra Khalid ${ }^{6,7}$

\begin{abstract}
Background: Dengue is becoming more common in Pakistan with its alarming spreading rate. A historical review needs to be carried out to find the root causes of dengue dynamics, the factors responsible for its spread and lastly to formulate future strategies for its control.

Methods: We searched (January, 2015) all the published literature between 1980 and 2014 to determine spread/ burden of dengue disease in Pakistan.

Results: A total of 81 reports were identified, showing high numbers of dengue cases in 2010, 2011, and 2013. The tendency of dengue to occur in younger than in older age groups was evident throughout the survey period and all four serotypes were recorded, with DENV1 the least common. Most dengue hemorrhagic fever (DHF) cases fell in the 20-45 years age range. High frequencies tended to be observed first in the Southern coastal region characterized by mild winters and humid warm summers and then the disease progressed towards the lowland areas of the Indus plain with cool winters, hot summers and monsoon rainfall. Based on this survey, new risk maps and infection estimates were identified reflecting public health burden imposed by dengue at the national level.

Conclusions: Our study showed that dengue is common in the three provinces of Pakistan, i.e., Khyber Pakhtunkhwa (KP), Punjab and Sindh. Based on the literature review as well as on our study analysis the current expansion of dengue seems multifactorial and may include climate change, virus evolution, and societal factors such as rapid urbanization, population growth and development, socioeconomic factors, as well as global travel and trade. Due to inadequate remedial strategies, effective vector control measures are essential to target the dengue vector mosquito where high levels of human-vector contact occur. The known social, economic, and disease burden of dengue is alarming globally and it is evident that the wider impact of this disease is grossly underestimated. An international multisectoral response, outlined in the WHO Global Strategy for Dengue Prevention and Control, 2012-2020, is now essential to reduce the significant influence of this disease in Dengue endemic areas. Overall gaps were identified in knowledge around seroprevalence, dengue incidence, vector control, genotype evolution and age-stratified serotype circulation.
\end{abstract}

\footnotetext{
* Correspondence: Abu_amna2013@hotmail.com

${ }^{1}$ Department of Parasitology, Zhongshan School of Medicine, Sun Yat-sen

University, Guangzhou 510080, Guangdong, China

2Sun Yat-sen University-Michigan State University Joint Center of Vector

Control for Tropical Diseases, Zhongshan School of Medicine, Sun Yat-sen

University, Guangzhou 510080, Guangdong, China

Full list of author information is available at the end of the article
}

(c) The Author(s). 2018 Open Access This article is distributed under the terms of the Creative Commons Attribution 4.0 International License (http://creativecommons.org/licenses/by/4.0/), which permits unrestricted use, distribution, and

reproduction in any medium, provided you give appropriate credit to the original author(s) and the source, provide a link to the Creative Commons license, and indicate if changes were made. The Creative Commons Public Domain Dedication waiver (http://creativecommons.org/publicdomain/zero/1.0/) applies to the data made available in this article, unless otherwise stated. 


\section{Background}

Dengue is a systemic mosquito-borne infectious disease caused by dengue virus (DENV) which has four common and genetically distinct serotypes $[1,2]$. More than $50 \%$ of the human population lives in dengue endemic areas [3-6]. About 50 to 200 million dengue cases with 500,000 incidences of dengue hemorrhagic fever and over 20,000 deaths are being documented every year around the globe [7]. The annual economic burden of dengue is estimated at US\$950 million and the disability-adjusted life year's value is 372 (210-520) per million residents $[8,9]$.

Dengue is thought to be expanding in Pakistan. The first dengue case was reported from Hub, Baluchistan Province in 1960, when the estimated population of Pakistan was 45.9 million. The total number of reported dengue cases for the 1960-1980 period was only 12 [10-13]. The first serologically and virologically confirmed dengue outbreak was reported from Karachi in 1994 [10]. Since 1960, the population of Pakistan gone up to 188.2 million (2014), while the total number of reported dengue cases has increased up to 74,495, with 690 reported fatalities. The factors contributing to the nationwide spread of dengue virus and the increase in dengue incidence are poorly understood.

We have therefore, undertaken a comprehensive compilation of dengue cases from published data and known records in the country, and used a modeling framework to understand dengue prevalence and risk. We have considered socioeconomic, epidemiological and demographic factors, including sero-prevalence, serotype distribution and dengue vector transmission. In this review, we have also discussed possible routes of incursion of dengue to non-infected areas.

\section{Methods}

Literature searching and analysis protocols followed the guidelines for "preferred reporting items of systematic reviews and meta-analyses" (PRISMA) [14]. Our searching strategy primarily was for dengue incidence and secondarily for dengue vectors. The protocol was registered on PROSPERO (managed by the Centre for Reviews and Dissemination, University of York) an internationally developed database of registered systematic reviews in health and social care. (http://www.crd.york.ac.uk/ PROSPERO/display_record.asp?ID=CRD42015016696).

\section{Search strategy and selection criteria}

As of January 2015, we searched several databases, such as Science Citation Index, Science Citation Index Expanded (SciSearch), Journal Citation Reports/Science Edition, Medline, SCOPUS, EMBASE, Google Scholar, CSA, ProQuest, CAB International, Biological Abstracts, BIOSIS, CAB Abstracts, CSA Environmental Sciences,
Biology \& Environmental Sciences, EBSCO Discovery Service, EM Biology, Global Health, PubMed, and Zoological Records. The published databases were accessed by using the terms dengue, dengue fever, climate change, dengue hemorrhagic fever (DHF), climate irregularities, risk factors and dengue fever, dengue fever and modeling, vector borne diseases, vector borne disease modeling, infectious disease surveillance early warning systems, and secondarily by choosing the terms dengue vectors, Aedes aegypti and Aedes albopictus, Pakistan. The search included studies published from January 1994 to December 2014 because dengue surveillance was established during this period.

\section{Selection criteria}

The articles were selected based on the following inclusion criteria: 1) peer-reviewed, 2) available full text articles, 3) published in English, and 4) only studies considering the distribution of dengue risk with increase in population along with socioeconomic, mosquito density, epidemiological and demographic factors, sero-prevalence, serotype distribution and dengue vector transmission, dengue case/ infection or incidence. The rationale for inclusion criteria was to focus on the increase in population, mosquito density, and socioeconomic, ecological, epidemiological and demographic factors associated with dengue transmission. Articles not meeting the above criteria were excluded (Fig. 1).

\section{Quality assessment and potential biases}

Quality of each study was assessed through the combined criteria suggested by Effective Public Health Practice Project (EPHPP)1 and Wells et al. [15]. The quality of each study was determined across seven metrics: selection, study design, data collection, observational time period, interpretation of factors, and full description of dengue diagnosis. Potential bias within the studies was also determined.

We mostly could not find human population data for respective areas where dengue cases (across a time course) were reported in the literature, and the literature we searched reported dengue cases rather than dengue incidence. This is a limitation of the current study. However, we developed a relative risk ratio map for 20112013, a period for which human population data was available [16-18]. Risk ratios were calculated with reference to the population and area of a region for 20112013 as shown in Fig. 2. The relative risk ratio was computed to model spatially varying relationships between dengue incidences, population, and locality.

\section{Results and discussion}

A total of 81 out of 125 research reports were included in this review (Fig. 1). Dengue was found to be common 


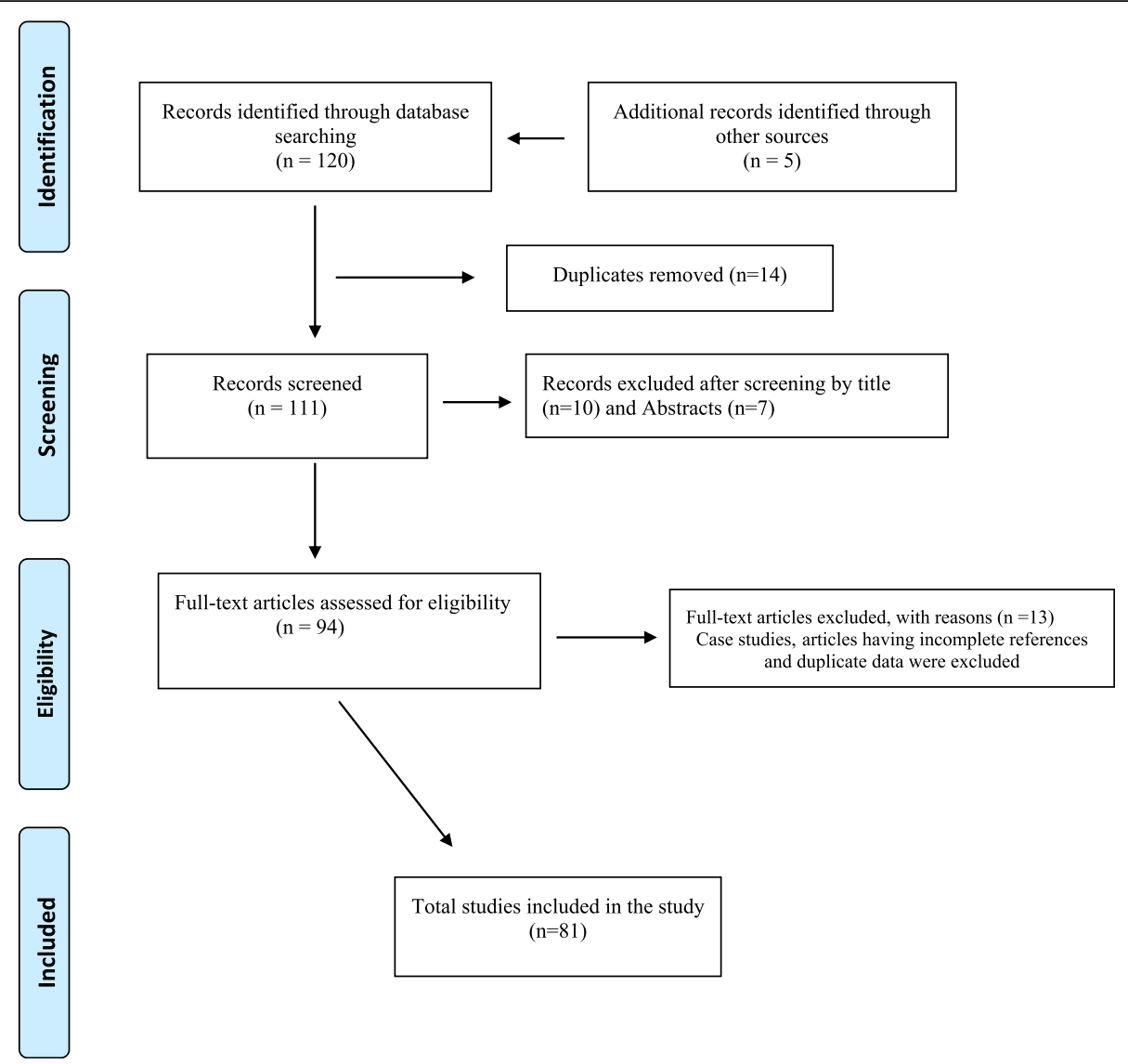

Fig. 1 Results of literature search and evaluation of identified studies according to PRISMA

in three provinces, Khyber Pakhtunkhwa (KP), Punjab and Sindh. There was some variation in disease burden which seems to be strongly influenced by vector presence, ecological factors like rainfall, temperature, travel and trade, socio-demographic factors and the degree of urbanization [16-20]. The following sections provide a detailed picture of factors influencing dengue incidence in Pakistan.

\section{Dengue vectors in Pakistan}

Ae. aegypti was recorded for the first time by Barraud in 1934 [21] from Peshawar, Dera Ismail Khan, Lahore, Larkana and Karachi and thereafter from Lahore by Aslam Khan [22] (during 1969 and 1971). Qutubuddin [23] reported it from the Kohat-Hangu valley in 1949. After 1950, Ae. aegypti along with malarial mosquitoes seemed to have been suppressed [24] and until the 1980's this species was not documented again [25]. In 1996 Ae. aegypti was reported in northern Pakistan from Landi Kotal near Peshawar in KP province [24] and from Karachi in 2010 [26, 27]. Both Ae. aegypti and Ae. albopictus were reported from Murree hills in the districts of Punjab [28], from Sindh by Mukhtar et al. [16] and from Charsadda, Nowshera, Peshawar, Mardan and Buner districts of KP in 2014-2015 by Khan et al. [29, 30]. It seems that both Ae. aegypti and Ae. albopictus have not only started re-invading formerly occupied areas (i. e. Karachi, Peshawar and Lahore) but have also started spreading to new areas where they were not present before (e.g. Attock, Haripur, Hasanabdal, Taxilla, Rawalpindi, Gujranwala, Sheikhupura, Faisalabad, Multan and Hyderabad) [5, 12, 31] (Table 1). Ae. aegypti and Ae. albopictus have been reported breeding in almost all types of artificial containers especially in tires [32] and other outdoor water storage containers [4]. Both species occur in different geographical areas of the country starting from sea level (Karachi) to higher altitudes (northern areas). In Southern parts of the country (24$50 \mathrm{~m}$ above sea level), only Ae. aegypti is prevalent, whereas in northern/sub mountainous areas (500-600 m above sea level with upper limit of $2500 \mathrm{~m}$ ), Ae. albopictus seems dominant. In the central part of the country, both the species co-exist but Ae. aegypti appears dominant over Ae. albopictus [17].

\section{An overview of dengue in Pakistan}

Dengue serotype 2 was detected in 1987 and serotype 1 in 1990s [32]. The first outbreak was recorded in 


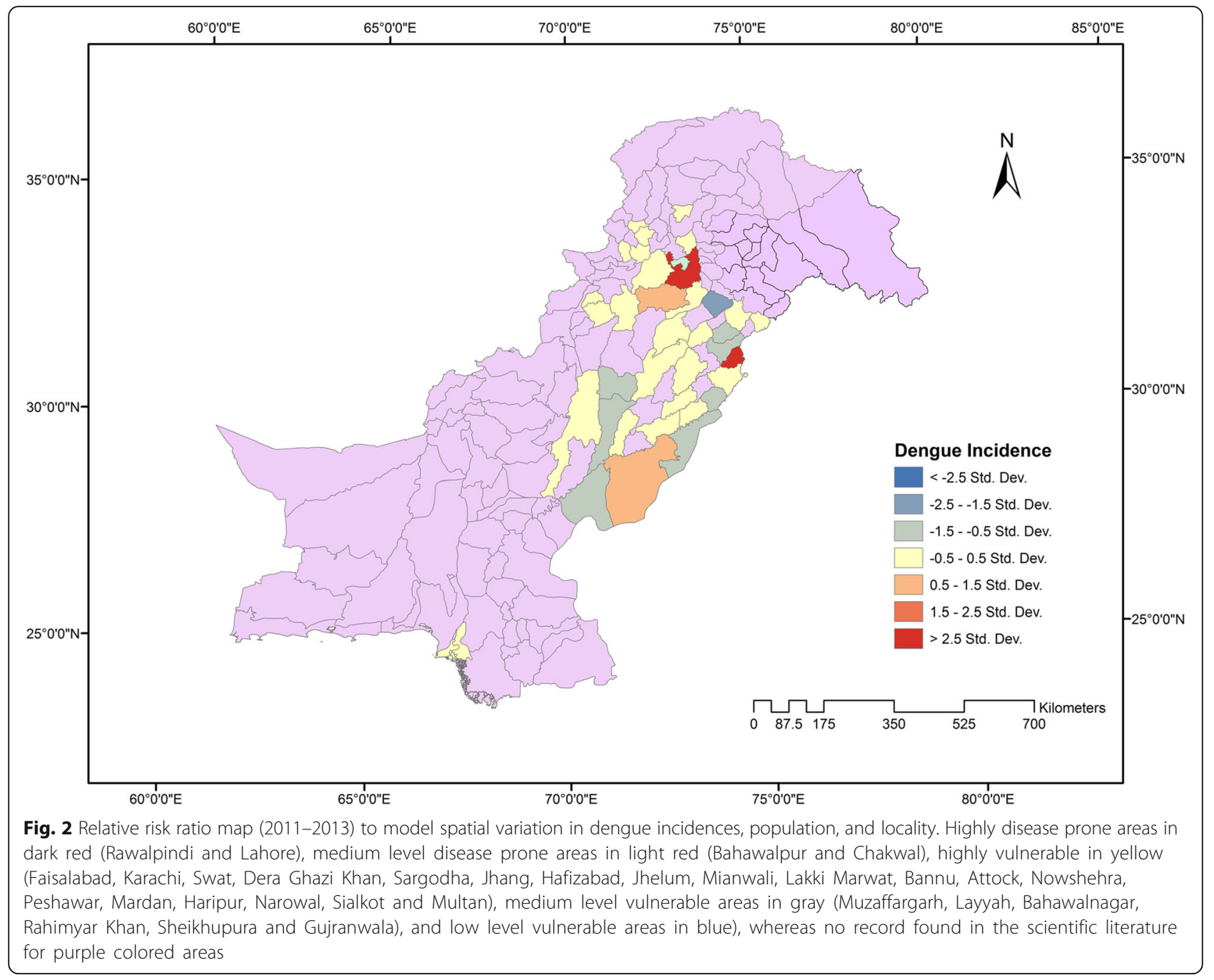

Karachi during 1994 caused by circulating DENV-1 and 2 [10, 11, 33-35]. Another dengue outbreak was documented in Karachi during 2005 in which DENV-1 and 2 were the predominant serotypes, with newly introduced DENV-3 also detected [33, 36, 37]. Three dengue virus serotypes $(2,3$, and 4 ) were observed during 2008 in Lahore $[33,38,39]$. The largest dengue outbreak was reported during 2011 in Lahore with 22,562 dengue cases and 363 fatalities $[1,2,5,40]$. The second largest epidemic occurred during 2013 in Swat (KP province) with 8343 dengue cases and 57 deaths (Fig. 3). The predominant circulating serotypes reported were DENV-2, 3 \& 4 in Punjab during 2011, and DENV-2 \& 3 in Swat, KP during 2013 [5, 39, 41] (Tables 2 and 3).

The highest numbers of confirmed dengue cases in Pakistan were noted during 2010 and 2011, with 37,512 and 10,416 cases respectively (Table 2). Even though dengue epidemics varied across the years, there was an increasing trend of dengue over time in Pakistan, suggesting a worsening situation since 2005 (Fig. 3). From
1994 to 2013, nine national epidemics (Table 3) occurred $[5,33,39,41,42]$. The reported dengue cases and fatality rates were very high in Lahore (2011) and Swat (2013) as compared to other Asian regions. However, the number of dengue cases reported in Pakistan is lower than other countries in Asia, South East Asia and Americas [43-45]. According to available climatic data [17], abnormal environmental conditions prevailed in the country during 2010, with heavy rains and flooding. Flood water accumulation in low lying areas (Lahore) of the country plus very high in-flow of people from surrounding cities for employment and education purposes [18] might be the reason for rise in dengue. Moreover, infested eggs of Aedes might have been carried with flood water and calm winds, resulting in dengue spread. Lahore, being the congested city coupled with lack of awareness and preparedness at the government level may have been the main reasons for high fatality rates during 2011. Additionally, Lahore borders India, and serotypes isolated from epidemics in Lahore show close 
Table 1 Dengue Vectors (mosquitoes) and their introduction to Pakistan

\begin{tabular}{|c|c|c|c|c|c|}
\hline First Author & Year & Finding & Areas & Found in & Ref \\
\hline Barraud & 1934 & Culicine fauna of British India was published & $\begin{array}{l}\text { Peshawar, Dera Ismail Khan, Lahore, Larkana and } \\
\text { Karachi in west Pakistan }\end{array}$ & $1927-32$ & 21 \\
\hline Qutubuddin & 1960 & First detection of Ae. aegypti & Kohat-Hangu valley & 1949 & 23 \\
\hline Khan & $\begin{array}{l}1969, \\
1971\end{array}$ & $\begin{array}{l}\text { A check list on the names and taxonomic position } \\
\text { of Culicidae in Pakistan was produced }\end{array}$ & West Pakistan & 1960 & 22 \\
\hline Suleman & 1996 & $\begin{array}{l}\text { Suppression of Malaria and } \\
\text { Ae. aegypti }\end{array}$ & $\begin{array}{l}\text { All cities that encountered with Malaria and } \\
\text { Dengue in the past }\end{array}$ & After 1950's & 24 \\
\hline Kamimura & 1986 & Re-emergence of Malaria and Dengue & $\begin{array}{l}\text { All cities that encountered with Malaria and } \\
\text { Dengue previously }\end{array}$ & From 1980's & 25 \\
\hline $\begin{array}{l}\text { Suleman } \\
\text { Paul } \\
\text { Tariq } \\
\text { Tariq }\end{array}$ & $\begin{array}{l}1996 \\
1998 \\
2000 \\
2010\end{array}$ & Ae. aegypti & Landi Kotal, Karachi & 1996-1997 & $\begin{array}{l}24 \\
26 \\
27 \\
32\end{array}$ \\
\hline Mukhtar & 2011 & $\begin{array}{l}\text { Dominance of Ae. albopictus over } \\
\text { Ae. aegypti }\end{array}$ & $\begin{array}{l}\text { Northern/ sub mountainous areas (500-600 m } \\
\text { above sea level) }\end{array}$ & $2006-2010$ & 19 \\
\hline Mukhtar & 2011 & $\begin{array}{l}\text { Dominance of Ae. aegypti over } \\
\text { Ae. albopictus }\end{array}$ & Central Pakistan region & $2006-2010$ & 19 \\
\hline $\begin{array}{l}\text { Mukhtar } \\
\text { Qasam } \\
\text { Khan }\end{array}$ & $\begin{array}{l}2012 \\
2014 \\
2015\end{array}$ & $\begin{array}{l}\text { Ae. aegypti and } \\
\text { Ae. albopictus }\end{array}$ & $\begin{array}{l}\text { Muree hills, Charsadda, Nowshera, Peshawar, } \\
\text { Mardan and Buner districts }\end{array}$ & $\begin{array}{l}2012,2012- \\
13,2014\end{array}$ & $\begin{array}{l}18 \\
28 \\
29\end{array}$ \\
\hline $\begin{array}{l}\text { Khan } \\
\text { Khan } \\
\text { Rasheed }\end{array}$ & $\begin{array}{l}2016 \\
2017 \\
2013\end{array}$ & Ae. aegypti and Ae. albopictus & $\begin{array}{l}\text { Karachi, Peshawar, Lahore, Attock, Haripur, } \\
\text { Hasanabdal, Taxilla, Rawalpindi, Gujranwala, } \\
\text { Swat, Buner, Sheikhupura, Faisalabad, } \\
\text { Multan and Hyderabad }\end{array}$ & 2013, 2014-15 & $\begin{array}{l}5 \\
31 \\
13\end{array}$ \\
\hline
\end{tabular}

resemblance with serotypes prevailing in India [43]; thus we cannot rule out the possibility of this serotype to be introduced. The introduction of the new serotypes DENV-3 (2005) and DENV-4 (2008) into Lahore likely increased the severity of disease in susceptible individuals.

The dengue outbreak of Swat occurred 2 years later than that of Lahore. The Swat region suffered from an unstable political environment and outflow of residents during 2008-9. Mud houses and tents were used by internally displaced people (IDPs) and many resided in open places close to standing water. The IDPs suffered from various enteric, digestive and intestinal diseases and were re-settled during 2010-11 but had lost their jobs. A severe dengue outbreak occurred 2 years post settlement among these IDPs. Khan et al. [4, 5, 7, 21, 30, 31] have reported transportation of old tires between Lahore, Karachi and Swat as the primary reason of this dengue outbreak in Swat, but severity of the disease was exacerbated by poor living conditions. Moreover, Swat is a mountainous area visited by people from all over the country especially Lahore, Rawalpindi, Faisalabad (Punjab) and Karachi (Sindh). This influx of visitors increased after the resettlement of IDPs in Swat and contributed to the introduction of virus in to Swat. The mild climatic condition of Swat provides suitable breeding conditions for Aedes [4, 5, 30, 31].

\section{Dengue epidemiology and ecological zones in Pakistan}

The geographic structure of Pakistan ranges from a mountainous northern part to a southern part with coastal plains that can be divided into four climatic regions: a highland climate, low land climate, costal climate and arid climate (Fig. 4). Zone A represents a hilly area, constituting the northern, north-west and the mountains of western region. Zone $\mathrm{B}$ represents the lower region (the Indus plain). Zone $\mathrm{C}$ encompasses coastal regions (Karachi coast, Makran coast and Indus Delta through the Rann of Kutch), while Zone D includes deserts of south eastern and south western Baluchistan having arid climate.

We collated regional (published) data from all the four provinces and climatic zones of Pakistan. Except one study [22], no published data was found for the south western region (Baluchistan). The reports indicate that dengue started in the coastal part of the country during 1980, moved to the lowland and finally to the highland climatic zones. The disease established in the coastal climate characterized by mild winter, humid and warm summers during the first 15 to 20 years (1980-2000) and then spread to the lowland areas of Indus plain characterized by cool winters, hot summers and monsoon rainfall. Karachi is one of the most populated cities in the coastal region of the country. It experienced the first dengue outbreak during 1994 [10]. Punjab and part of KP provinces are situated in the lowland Indus plain. 


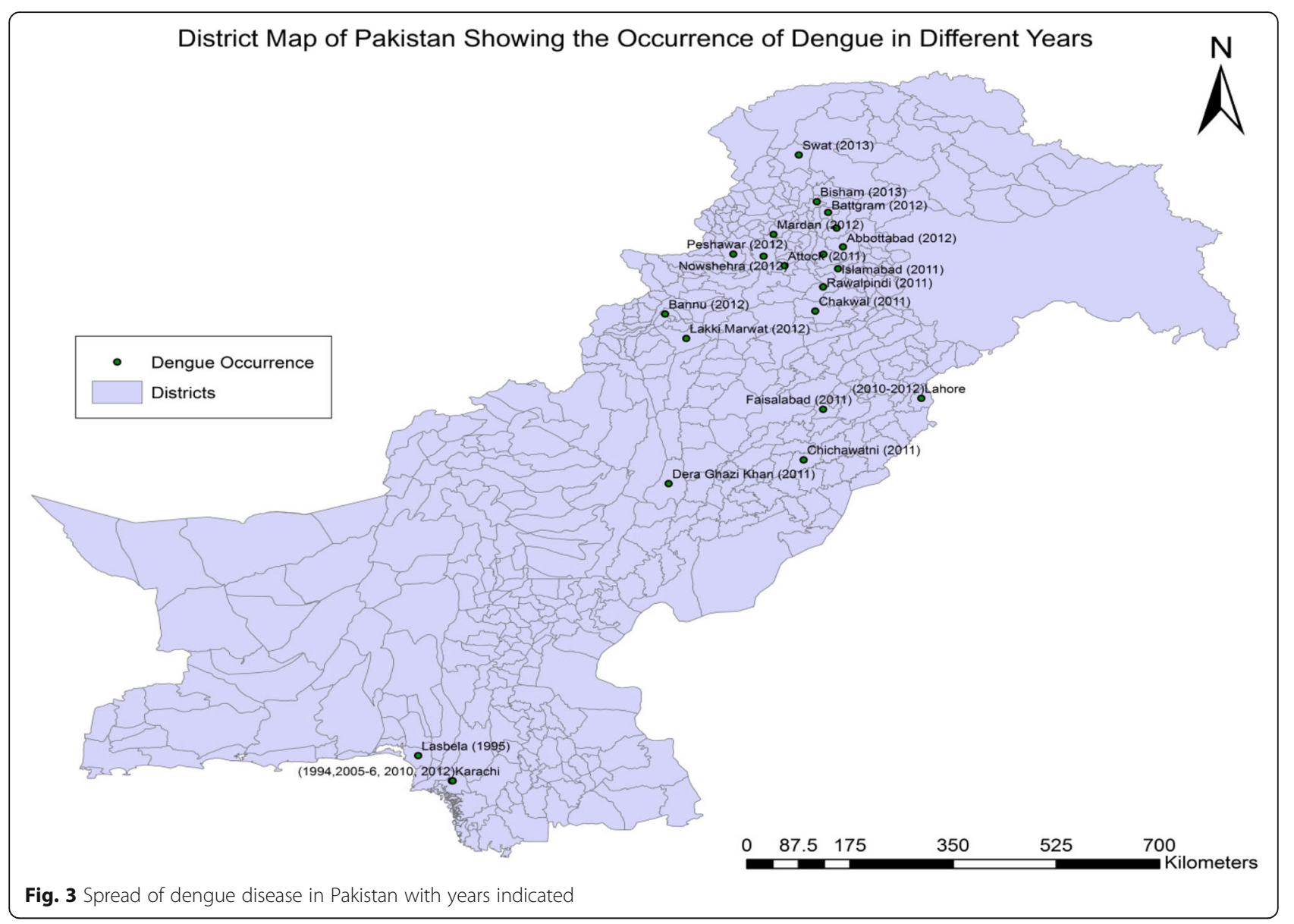

During 2010-11, Punjab and especially Lahore were severely affected by dengue, followed by Faisalabad, Rawalpindi and some parts of KP [34, 35, 38, 46-50] and later on Swat in the north.

Aedes has extended its geographic distribution during the last 35-year review period, resulting in an increased number of dengue cases in all climatic zones of Pakistan. Figure 5 shows the distribution of dengue in different cities/provinces of Pakistan over the years since its first occurrence in the country. Initially in the survey, the coastal areas of Southeast (Karachi and Hub in Sindh and Baluchistan provinces) were highly affected by dengue, while from 2009 the highest number of cases were documented from the lowland Indus delta plain area (Lahore, Punjab province). Dengue cases reported in the southern coastal city (Karachi) were consistently lower than in other regions [51-55].

\section{Demographic patterns and dengue disease in Pakistan}

The available data on dengue showed a change in age distribution over time (Table 4). Young adults (3239 years) suffered highly from DF during 2003-2005 and 2011-2012 [1, 5, 34, 35, 51, 52]. However, in 1980s to 1994 , DF was recorded in children aged $<16$ years
[34, 35, 47, 56, 57]. During 2006-2008, most DHF cases were recorded for 42-45 year age group, whereas in 2013, more cases of dengue were recorded in the 21-40 year age group [58-60]. In 2010, maximum dengue infections were recorded in individuals of more than 18 years. There is no age data available for 2008. However, in general individuals between 30 and 40 years age group showed an increase in hospitalization rates. More men than women (Table 4) were affected by dengue disease throughout Pakistan [48, 61-64]. This trend differs to the distribution of documented cases across sexes in countries in Latin America and other Asian countries $[43,65,66]$.

\section{Distribution of virus serotypes}

Until 1983, dengue cases were diagnosed by rapid test kits. The use of polymerase chain reaction (PCRs) for the isolation of dengue virus was limited. From 1994 onward, the Ministry of Health documented isolates of dengue virus in the country and DENV-1 \& DENV-2 were observed. DENV-3 was reported in the 2005 epidemic and DENV-4 in 2008 (Table 4). The reports also indicate a shift to DENV-2 \& DENV-3 towards the end of the decade, with DENV-3 circulating as a dominant serotype in later epidemics. The data reveal similar 
Table 2 The recorded dengue incidences and deaths in Pakistan (1982-2014)

\begin{tabular}{llllll}
\hline Author & Year & No. of cases & Deaths & Found in & Reference \\
\hline Idrees & 2012 & 12 & 0 & 1982 & 34 \\
Rasheed & 2013 & & & & 12 \\
Jamil & 2007 & 145 & 1 & 1994 & 37 \\
Idrees & 2012 & 76 & 57 & 1995 & 34 \\
Rasheed & 2013 & 251 & 1 & 1997 & 12 \\
Mukhtar & 2011 & 1000 & 17 & 2003 & 19 \\
Paul & 1998 & 25 & 0 & 2004 & 32 \\
Khanani & 2011 & 3940 & 21 & 2005 & 70 \\
Wasay & 2008 & & & & 54 \\
Rasheed & 2013 & 3000 & 52 & 2006 & 12 \\
Khalid & 2014 & 1208 & 22 & 2007 & 79 \\
Ali & 2013 & 2035 & 30 & 2008 & 58 \\
Khan & 2010 & 1099 & 16 & 2009 & 63 \\
Humayun & 2010 & 10,416 & 51 & 2010 & 39 \\
& & 37,512 & 363 & 2011 & \\
Khalid & 2014 & 4833 & 2 & 2012 & 79 \\
Khalid & $2015 a$ & 8343 & 57 & 2013 & 16 \\
Khalid & $2015 b$ & 600 & 0 & 2014 & 17 \\
Khan & $2015 a$ & & & & 4 \\
Khan & $2015 b$ & & 690 & & 5 \\
Khan & 2016 & & 74,495 & 59 & \\
Total & & & & & \\
\hline
\end{tabular}

patterns of serotype distribution to the national trends with some local variation $[5,29]$. Most of the data was from the northeast part of the Sindh and Punjab Provinces $[47,51,52,67,68]$ and the central-west region of KP $[5,7,17,18,29,56]$. A parallel trend of serotype circulation was documented during 1960-2004 in the country (Tables 3 and 4). By 2012-13, nearly all dengue cases in the country were due to serotypes $2 \& 3$. In contrast, in the southeast region (including Lahore/Karachi), a prior shift in serotype may have happened with DENV-4 documented for 59\% of dengue cases in 2008. However, for the period 1960-1994, DENV-2 was the predominant serotype responsible for the disease in the country. In the northern region of Pakistan, the outbreaks during 2003-2011 were mainly attributed to DENV-2 (>50\%) along with DENV-1 and DENV-3 [11, 33, 38]. During 2012, DENV-2 (77.8\%) and DENV-3 (11.2\%) were the major serotypes. Within the stated period, we observed an increase in the frequency of national epidemics [71] and severity of dengue disease (Figs. $3 \& 5$, Table 4). Some authors have attributed disease severity in children due to change in DENV-2 and DENV-3 versus DENV-1 and DENV-4 [5, 29, 33]. Nonetheless, the change in serotypes circulation may not be the only reason but other factors, such as regional variations in serotypes, viral strain virulence, serotype-specific immunity in individuals of different age, and the population density of Aedes mosquitoes may be involved. Several studies have documented clinical differences in dengue patients that could be linked with specific serotypes [2, 43, 76]. Patients infected by DENV-2 \& DENV-3 showed greater severity (in terms of clinical differences, number of dengue cases and fatalities) in the disease than those infected with DENV-1 or DENV-4 [5, 62]. However, the appearance of DENV-3 in the country is linked to increased outbreaks, while the emergence of DENV-4 is not associated with increased disease. Secondary infection by other serotypes has been reported to be a significant factor for the increase in disease (dengue) severity [1, 2, 56, 57].

\section{Socio-demographic factors}

An association of dengue disease with socio-economic, demographic and infrastructure features has been reported in many studies $[5,19,20,29]$. Other reports have demonstrated increased risk factors for dengue disease in individuals living in single-storey homes with a higher density of residents per household [1, 5, 27, 69-71]. Studies have also documented that the emergence and distribution dynamics of DENV-3 and viral transmission intensity is associated with increased density of human population as well as the presence of susceptible individuals. Increased urbanization, poor sewerage infrastructure, and improper piped water supplies have increased the risk of dengue disease in the residents [5, 72]. Figure 5 shows the dengue prone cities in different provinces of Pakistan, while the district-wise severity of dengue incidence with respect to their population and area has been shown in Fig. 2. Some research reports have identified that low income families with large number of children and women are more exposed to dengue than those with higher socio-economic status $[19,20]$. A report of sero-epidemiological study of 8000 randomly selected individuals during June-October (2013) in the same town confirmed that low income was an important factor for higher prevalence of dengue [4, 29]. The review indicates dissimilar patterns of dengue with time and space that suggests the involvement of diverse risk factors in transmission of the disease. Nonetheless, it is possible that the improper use of land, refugee influx, deforestation and unplanned urbanization also play a major role in dengue spread $[17,19]$.

\section{Genetic evolution and disease severity}

The increase in geographic expansion of dengue over time has been associated with the emergence of endemic and epidemic (genetically diversified) genotypes due to 
Table 3 The major dengue outbreaks documented in Pakistan

\begin{tabular}{llllll}
\hline Outbreak & Year & District & Province & Serotypes & Incidences: Deaths \\
\hline 1st & 1994 & Karachi & Sindh & $1 \& 2$ & $145: 1$ \\
2nd & 1995 & Hub & Baluchistan & $1 \& 2$ & $76: 57$ \\
3rd & 2003 & Haripur & KP & $1 \& 2$ & $717: 6$ \\
4 th & 2005 & Karachi & Sindh & $1,2 \& 3$ & $3940: 21$ \\
5 th & 2006 & Karachi & Sindh & $1,2 \& 3$ & $3940: 52$ \\
6 th & 2010 & Karachi \& Lahore & Sindh, Punjab & $1,2,3 \& 4$ & $10,416: 51$ \\
7 th & 2011 & Lahore & Punjab & $1,2,3 \& 4$ & $37,512: 363$ \\
8 th & 2012 & Karachi, Lahore \& districts of KP & Sindh, Punjab, KP & $2 \& 3$ & $4833: 2$ \\
9th & 2013 & Swat and Besham & KP & $2 \& 3$ & $8343: 57$ \\
\hline
\end{tabular}

small evolutionary changes in the gene pool of serotypes $[2,72]$. The introduction of a new clade due to genetic changes in an area results in dengue epidemics (DHF and DSS) [33, 73]. Variation in serotypes/genotypes could reflect genetic bottlenecks and/or natural selection $[71,75]$. In Pakistan, heterogeneity in disease may be, at least in part, due to the repeated introduction of new strains of DENV from other parts of the world, resulting in a conversion from hypoendemicity to hyperendemicity $[4,29]$.

Serotype 1 has been circulating in Pakistan since before the 1990s, with two genotypes (I and IV). Genotype I is closely related to DENV-1 that was responsible for 2009-2010 dengue outbreaks in Sri Lanka [72].

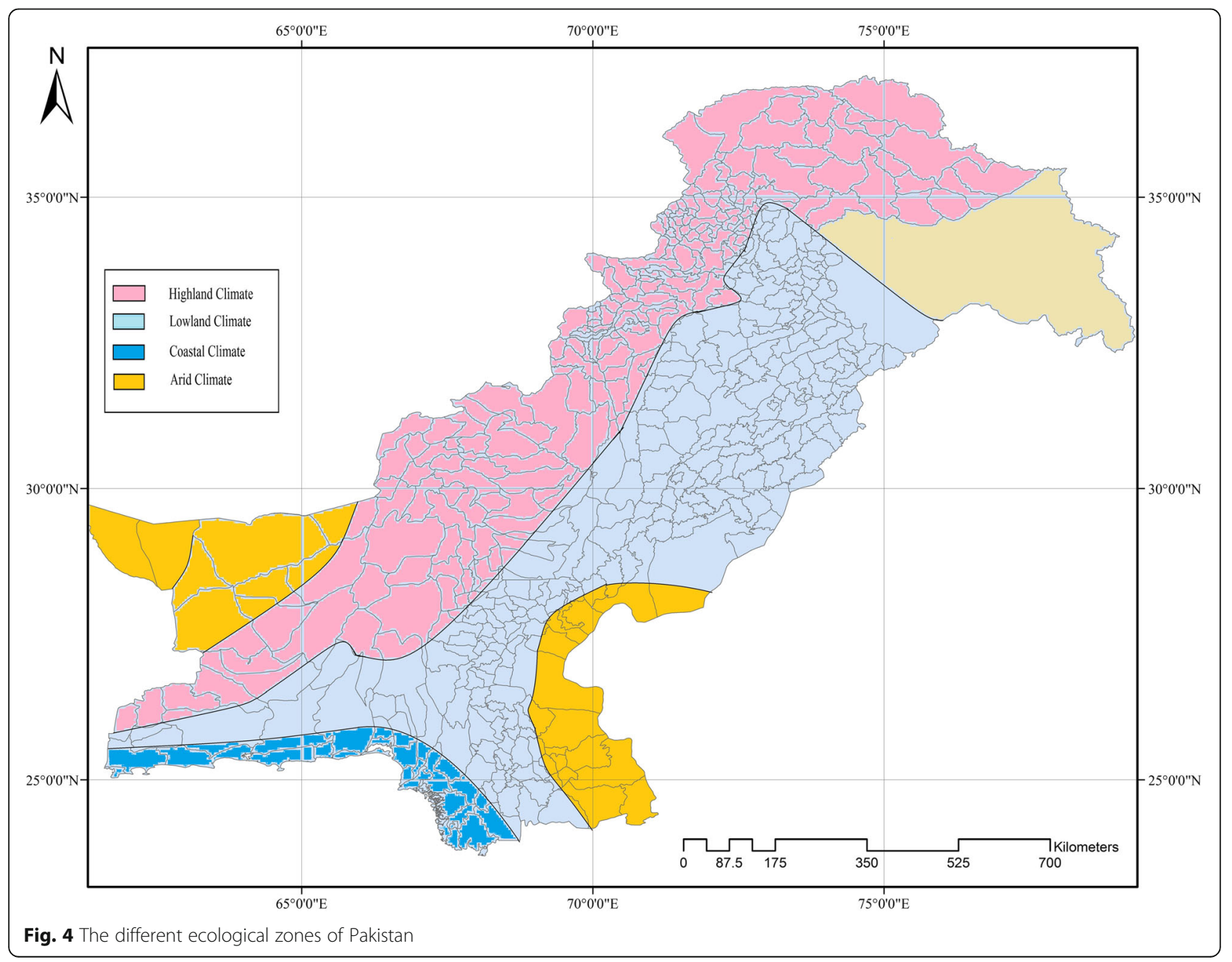




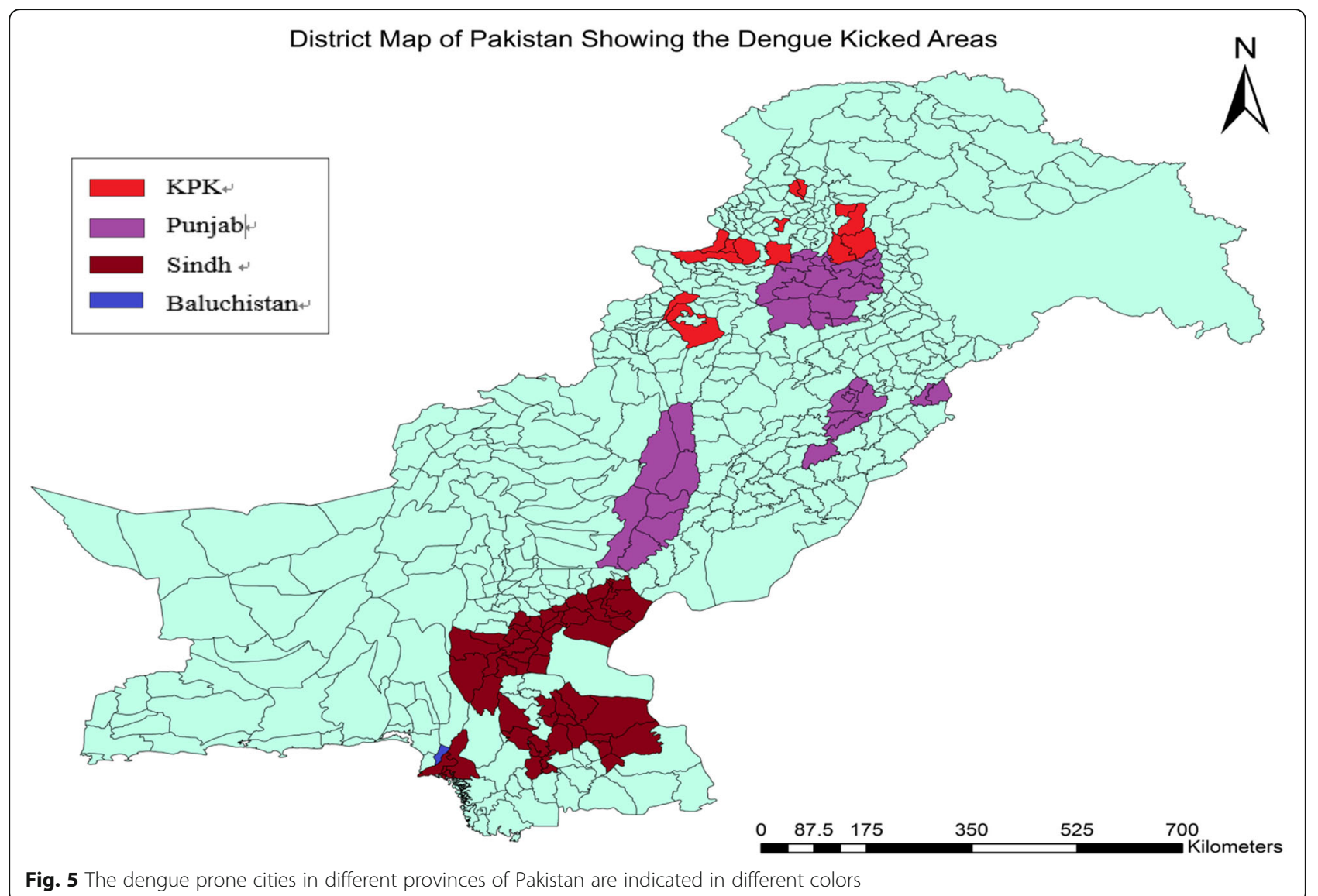

These strains have also been reported from Saudi Arabia, Thailand and Malaysia. Serotype 2 is the major circulating serotype in Karachi, Lahore, Faisalabad and Rawalpindi since 1994 [11]. There are repeated extinctions of serotype 2 and 3, which are replaced by new variants in the country [72]. DENV-2 has genotype IV (major) which was introduced in Pakistan from India in the late 1980s and from Sri Lanka around 2000 [2, 11]. This strain has also genetic resemblance with the Chinese (circulated during 1999 and 2000) and Saudi Arabian strains [41]. DENV-3 was first reported in 2005 dengue outbreak in Karachi, Pakistan. Serotype 3 isolated during the 2005 and 2006 outbreaks belong to genotype III and is most closely related to serotypes reported from India [36] and Sri Lanka $[11,72]$. Furthermore, all detected serotypes during 2006 to 2009 in Karachi and Hyderabad (Southern Pakistan) share genetic similarity with two Indian and one Chinese strains that circulated in the Indian subcontinent prior to their emergence in Pakistan during 2005-2006 [41]. Similarly, serotype 4 first detected during the 2008 dengue outbreak in Lahore, Pakistan [38] has highest resemblance with the strains detected in 2007 in Andra Pradesh (South India). Human (dengue infected) migration, vector dispersion and virus evolution are critical in the recent geographic increase of dengue to areas where the disease was not a major public health threat previously.

\section{Factors leading to disease spread in Pakistan Climate}

The growth and propagation of Aedes is dependent on climate and can be linked to dengue incidence in a region $[5,17,18]$. The gonotropic cycle of vector mosquito and the extrinsic incubation period of dengue virus are inversely related to high temperature, which increases egg laying activity and blood meal frequency, with increased risk of viral transmission [32]. A seasonal pattern of dengue linked to climate, occurs in different cities of Pakistan $[5,16,17,19,20]$. The highest dengue cases occur during July-September with more rainfall, optimum temperature and humidity, providing a conducive environment for breeding, survival and growth of Aedes mosquitoes [5]. It has been hypothesized that increases in the average temperature and humidity around the globe will increase the potential of dengue epidemic in approximately $50-60 \%$ of the global population by 2085 [75]. 
Table 4 Distribution of dengue according to year, age and sex, and the relative abundance of serotypes

\begin{tabular}{|c|c|c|c|c|c|c|}
\hline \multirow[t]{2}{*}{ Author } & \multirow[t]{2}{*}{ Year } & \multicolumn{3}{|l|}{ Main Findings } & \multirow[t]{2}{*}{ Found in } & \multirow[t]{2}{*}{ Reference } \\
\hline & & $\operatorname{RAS}^{a}(\%)$ & $M: F^{b}$ & Age years & & \\
\hline Khanani & 2011 & DENV-1, DENV-2(dominant) & N/A & $<16$ & 1960s-1994 & 70 \\
\hline Paul & 1998 & N/A & 95: 5 & 42 & 1995 & 32 \\
\hline \multirow{5}{*}{$\begin{array}{l}\text { Khan } \\
\text { Koo } \\
\text { Fatima } \\
\text { Khanani } \\
\text { Khaskheli } \\
\text { Wasay } \\
\text { Humayun }\end{array}$} & \multirow{5}{*}{$\begin{array}{l}2010 \\
2013 \\
2011 \\
2011 \\
2010 \\
2008 \\
2010\end{array}$} & N/A & $63.2: 36.8$ & 32 & 2003 & \multirow{5}{*}{$\begin{array}{l}63 \\
42 \\
57 \\
43 \\
54 \\
39\end{array}$} \\
\hline & & DENV-2 (65), DENV-3 (34) DENV-1 (1) & $67: 33$ & $20-40$ & $2004-2005$ & \\
\hline & & DENV-2 (50), DENV-3 (50) & 49:12 & 45 & 2006 & \\
\hline & & DENV-2 (50), DENV-3 (50) & N/A & 44.7 & 2007 & \\
\hline & & DENV-2 (29), DENV-3 (12) DENV-4 (59) & N/A & N/A & 2008 & \\
\hline Khanani & 2011 & & & & & 70 \\
\hline Suleman & 2017 & DENV-2, DENV-3 & 27.1:39 & $21-30$ & 2009 & 15 \\
\hline Khanani & 2011 & & & & & 70 \\
\hline Usman & 2011 & DENV-2 (60), DENV-1(20) & 60.4: 30.6 & $18-60$ & 2010 & 77 \\
\hline Suleman & 2017 & DENV-3 (20) & & & & 15 \\
\hline Khan & 2013 & DEN-2 (91.03), DENV-2 \& 3 (3.97), DENV-1(5) & & & & 75 \\
\hline Ahmed & 2013 & & & & & 35 \\
\hline Ali & 2013 & & & & & 58 \\
\hline Idrees & 2012 & & $80: 20$ & $21-40$ & 2011 & 77 \\
\hline Mukhtar & 2012 & & & & & 18 \\
\hline Koo & 2013 & & & & & 42 \\
\hline Suleman & 2017 & & & & & 15 \\
\hline Suleman & 2017 & & & & & 80 \\
\hline Khan & 2017 & DENV-2 (77.7), DENV-3 (11.2) & & & & 31 \\
\hline Mukhtar & 2012 & & $73: 26$ & $34-45$ & 2012 & 18 \\
\hline Suleman & 2017 & & & & & 80 \\
\hline Khan & $2015 a$ & DENV-3 (66), DENV-2 (34) & & & & 4 \\
\hline Khan & $2015 b$ & & $68.6: 31.3$ & $20-40$ & 2013 & 29 \\
\hline Suleman & 2017 & & & & & 80 \\
\hline Khan & 2016 & DENV-2 (35), DENV-3 (65) & & & & 5 \\
\hline Suleman & $2017 a$ & & $67.3: 32.7$ & $20-45$ & 2014 & 15 \\
\hline Suleman & $2017 b$ & & & & & 80 \\
\hline Khan & 2013 & & & & & 75 \\
\hline Ahmed & 2013 & & & & & 35 \\
\hline Ali & 2013 & & & & & 58 \\
\hline Idrees & 2012 & & & & & 78 \\
\hline Mukhtar & 2012 & & & & & 18 \\
\hline Khan & 2013 & & & & & 41 \\
\hline Koo & 2013 & & & & & 42 \\
\hline
\end{tabular}

${ }^{\mathrm{a}}$ RAS Relative abundance of serotypes ${ }^{\mathrm{b}} \mathrm{M}: \mathrm{F}$ Male and Female ratio N/A: Not available/reported

Globalization, travel, and trade factors

A change in climate may not be the only factor affecting dengue spread, but travel and trade may also be important. Increases in travel during the twentieth century have resulted in a 40-fold increase in dengue [34, 70]. Overcrowded airports provide ideal mosquito breeding spots and DENV distribution points when people travel to different countries [75]. The range of adaptations of Aedes mosquitoes for breeding and surviving within trapped water in old tires and other goods has increased the risk of dengue in the past few decades; and the situation may be aggravated as more automobiles are used globally [41, 64, 71]. 


\section{Socioeconomic factors}

Socioeconomic factors such as population growth, improper urbanization, settlement and other socioeconomic constraints on control measures contributes to the recent spread of dengue [71]. The construction of necessary infrastructures for water collection, storage, and disposal in urban and peri-urban settlements has provided favorable ecological niches and breeding sites for dengue vectors. The increase in population density of mosquito as well as humans, as part of urban population growth, has increased the vectoral capacity of vector mosquitoes and hence the transmission of dengue [29, 30]. A study by Khalid and Ghaffar [17] conducted in two cities, Rawalpindi and Islamabad, found that urbanization, hydrological conditions (stream flow and stream density), House Density Index (HDI) including house type, urbanization types, indoor and outdoor conditions overall form a complex structure to promote dengue occurrence and transmission in these two areas. The energy crises in Pakistan have aggravated the situation further where the low income families are compelled to sleep in the open environment and thus are exposed to mosquitoes. The government is struggling to overcome this situation and has increased its spending on construction of hydropowered and nuclear powered stations for generating electricity $[48,69-82]$.

\section{Limitations of the study}

While this review has attempted to be comprehensive, several limitations exist around existing studies. No data was available on the seroprevalence of virus prior to 2010. Similarly, human population data and the number of dengue case were often unclear over the study period, and dengue cases rather than incidences were reported.

\section{Conclusion}

Currently more than 125 countries including Pakistan are dengue endemic. This review showed dengue to be common in three provinces of Pakistan, i.e., KP, Punjab and Sindh. The expansion of dengue in Pakistan is likely to be due to multiple factors which may include a change in climate, evolution of virus, and social factors like increased urbanization, higher population growth and development, socioeconomic factors, and worldwide travel and trade. More effective control measures for dengue mosquitoes are necessary in locations where humans interact with vector species. Globally, dengue is expanding to non-endemic areas. The Worldwide Strategy for Prevention and Control of Dengue as outlined by WHO (2012-2020), needs to be implemented to limit the spread and impact of this disease. Recommended control measures for dengue may include population (vector) suppression using the ecofriendly control techniques, utilization of air conditioning, window/door screening in homes and offices, improved water storage practices and waste material disposal infrastructure, which can reduce the breeding sites of dengue vectors.

\section{Abbreviations \\ DHF: Dengue Hemorrhagic Fever; HDI: House Density Index; IDPs: Internally Displaced Peoples; KP: Khyber Pakhtunkhwa}

\section{Acknowledgements}

The authors thank Dr. Farman Ali (Agriculture Department, Abdul Wali Khan University Mardan, Pakistan) and Prof. Ary Hoffmann FAA (School of Biosciences, the University of Melbourne, Australia) for critically reviewing the manuscript.

\section{Funding}

This study is not supported by any funding source. This study is supported by the National Research and Development Plan of China

(No.2016YFC1200500) and 111 project (B12003).

\section{Availability of data and materials}

All the data generated or analyzed during this study are included in this manuscript.

\section{Authors' contributions}

Conceived and designed the experiments: JK. Extracted the data: JK. Analyzed the data: JK. Contributed reagents/materials/analysis tools: JK. Wrote the paper: JK IK. Critically revised the MS and provided suggestions and comments on the manuscript: IK JK AG BK. Performed the analysis on the extracted data from the literature and produced graphs and maps: BK JK. Interpreted and adjusted the figures in the manuscript: JK BK. All authors read and approved the final manuscript.

Ethics approval and consent to participate Not applicable.

\section{Competing interests}

The authors declare that they have no competing interests.

\section{Publisher's Note}

Springer Nature remains neutral with regard to jurisdictional claims in published maps and institutional affiliations.

\section{Author details}

'Department of Parasitology, Zhongshan School of Medicine, Sun Yat-sen University, Guangzhou 510080, Guangdong, China. ${ }^{2}$ Sun Yat-sen University-Michigan State University Joint Center of Vector Control for Tropical Diseases, Zhongshan School of Medicine, Sun Yat-sen University, Guangzhou 510080, Guangdong, China. ${ }^{3}$ Department of Zoology, Abdul Wali Khan University Mardan (AWKUM), Mardan, Khyber Pakhtunkhwa, Pakistan. ${ }^{4}$ Nuclear Institute for Food and Agriculture (NIFA), Peshawar, Khyber Pakhtunkhwa, Pakistan. ${ }^{5}$ Department of Meteorology, COMSATS University (CUI), Islamabad, Pakistan. ${ }^{6}$ Evolution and Ecology Program, International Institute for Applied Systems Analysis, Laxenburg, Austria. ${ }^{7}$ Earth System Physics, The Abdus Salam, International Centre for Theoretical Physics, Trieste, Italy. ${ }^{8}$ Key Laboratory of Tropical Diseases and Control of the Ministry of Education, Guangzhou 510080, China.

Received: 25 April 2018 Accepted: 5 June 2018

Published online: 15 June 2018

\section{References}

1. Khan J, Ghaffar A, Khan SA. The changing epidemiological pattern of dengue in swat, Khyber Pakhtunkhwa. PLoS One. 2018; https://doi.org/10. 1371/journal.pone.0195706.

2. Akram M, Fatima Z, Purdy MA, Sue A, Saleem S, et al. Introduction and evolution of dengue virus type 2 in Pakistan: a phylogeographic analysis. Virology J. 2015;12:148.

3. Bhatt S, Gething PW, Brady OJ, Messina JP, Farlow AW, et al. The global distribution and burden of dengue. Nature. 2013;496:504-7. 
4. Khan J, Khan A. Incidence of dengue in 2013: dengue outbreak in district swat, Khyber Pakhtunkhwa, Pakistan. Inter J Fauna Biolo Stud. 2015;2:1-7.

5. Khan J, Khan I, Amin I. A comprehensive entomological, serological and molecular study of 2013 dengue outbreak of swat, Khyber Pakhtunkhwa, Pakistan. PLoS One. 2016;11(2):e0147416. https://doi.org/10.1371/journal. pone.0147416.

6. Organization WH, Research SPf, Diseases TiT, Diseases WHODoCoNT, Epidemic WHO, et al. Dengue: guidelines for diagnosis, treatment. In: Prevention and control: World Health Organization; 2009.

7. Khan S, Ullah R, Saleem M, Bilal M, Rashid R, et al. Raman spectroscopic analysis of dengue virus infection in human blood sera. Optik Int J Light Elect Optics. 2016;127:2086-8.

8. Shepard DS, Undurraga EA, Halasa YA. Economic and disease burden of dengue in Southeast Asia. PLoS Negl Trop Dis. 2013;7:e2055.

9. Chan T-C, Hu T-H, Hwang J-S. Daily forecast of dengue fever incidents for urban villages in a city. Int J Health Geogr. 2015;14:1.

10. Chan Y, Salahuddin N, Khan J, Tan H, Seah C, et al. Dengue haemorrhagic fever outbreak in Karachi, Pakistan, 1994. Trans R Soc Trop Med Hyg. 1995; 89:619-20.

11. Fatima Z, Akram M, Raza SM, Ali L, Hussain A, Amin I, Shahid M, Khubaib B, Saleem S, Nasir B. Dengue virus serotype 2 (DEN-2): the causative agent of 2011-dengue epidemic in Pakistan. Am J Biomed Sci. 2012;4(4):307-15.

12. Rasheed $S$, Butlin R, Boots M. A review of dengue as an emerging disease in Pakistan. Public Health. 2013;127:11-7.

13. Rasheed S, Boots M, Frantz A, Butlin R. Population structure of the mosquito Aedes aegypti (Stegomyia aegypti) in Pakistan. Med Veter Entom. 2013;27: 430-40.

14. Moher D, Liberati A, Tetzlaff J, Altman DG. Preferred reporting items for systematic reviews and meta-analyses: the PRISMA statement. Ann Intern Med. 2009;151:264-9.

15. Wells GA, Shea B, O'Connell D, Petersen J, Welch V, Losos M, Tugwell P. The Newcastle-Ottawa Scale (NOS) for assessing the quality of nonrandomized studies in meta-analyses. Ottawa: Ottawa Hospital Research Institute; 2011.

16. Suleman M, Lee H-W, Zaidi SSZ, Alam MM, Nisar N, Aamir UB, Sharif S, Shaukat S, Khurshid A, Angez M, et al. Preliminary Seroepidemiological survey of dengue infections in Pakistan, 2009-2014. Infect Dis Poverty. 2017; 6(1):48.

17. Khalid B, Ghaffar A. Dengue transmission based on urban environmental gradients in different cities of Pakistan. Int J Biometeorol. 2015;59:267-83.

18. Khalid B, Ghaffar A. Environmental risk factors and hotspot analysis of dengue distribution in Pakistan. Int J Biometeorol. 2015;59:1721-46.

19. Mukhtar F, Salim M, Farooq A. Outbreak of dengue fever in Lahore: study of risk factors. J Ayub Med Coll Abbottabad. 2012;24:99-101.

20. Mukhtar M, Tahir Z, Baloch TM, Mansoor F, Kamran J. Entomological investigations of dengue vectors in epidemic-prone districts of Pakistan during 2006-2010. Deng Bull. 2011:35

21. Khan GZ, Khan I, Khan IA, Alamzeb SM, et al. Evaluation of different formulations of IGRs against Aedes albopictus and Culex quinquefasciatus (Diptera: Culicidae). Asian Pac J Trop Biomed. 2016:20-9.

22. Barraud PJ (1934) The Fauna of British India, including Ceylon and Burma. Diptera. Vol. 5. Family Culieldae. Tribes Megarhinini and Culicini. The Fauna of British India, Including Ceylon and Burma Diptera Vol 5 family Culieldae tribes Megarhinini and Culicini.

23. Khan A (1972) The mosquitoes of Pakistan I/II. Mosquitoes Originally Described from Pakistan.

24. Qutubuddin M. Mosquito studies in the Indian subregion. Part I taxonomy-a brief review Pacif. Insects. 1960;2:133-47.

25. Suleman M, Arshad M, Khan K. Yellowfever mosquito (Diptera: Culicidae) introduced into Landi Kotal, Pakistan, by tire importation. J Med Entomol. 1996;33:689-93.

26. Kamimura K, Takasu T, Ahmed A. A survey of mosquitoes in Karachi area, Pakistan. J Pak Med Assoc. 1986;36:182.

27. Tariq RM, Zafar SN. Why the population of dengue vector mosquitoes is increasing day-by-day in Karachi and other areas of Sindh, Pakistan. Pak J Entomol. 2000:15:7-10

28. Tariq RM, Ahmed I, Qadri SS. Population dynamics and mechanical contro of denque vector mosquitoes Aedes aegypti and Aedes unilineatus in seven towns of Karachi. Pak J Entomol. 2010;25:21-6.

29. Qasim M, Naeem M, Bodlah I. Mosquito (Diptera: Culicidae) of Murree Hills, Punjab, Pakistan. Pak J Zool. 2014;46:523-9.
30. Khan J, Munir W, Khan B, Ahmad Z, Shams W, et al. Dengue outbreak 2013: clinical profile of patients presenting at DHQ Buner and THQ Shangla, Khyber Pakhtunkhwa, Pakistan. Biohelikon: Immun \& Dis 2015;3:a11.

31. Khan J, Shah M, Khan BT, Naeem M, Ismail M, Abbasi A, et al. A survey of adult and larval mosquito fauna in Tehsil Daggar and Gagra of District Buner, Khyber Pakhtunkhwa, Pakistan. Int J Mosq Res. 2015:1-5.

32. Khan J, Khan I, Ali I, lqbal A, Salman M. The role of vertical transmission of dengue virus among field-captured Aedes aegyptiand Aedes albopictus mosquitoes in Peshawar, Khyber Pakhtunkhwa, Pakistan. Pak J Zool. 2017; 49(3):777-84.

33. Paul RE, Patel AY, Mirza S, Fisher-Hoch SP, Luby SP. Expansion of epidemic denque viral infections to Pakistan. Int JInf Dis. 1998:2:197-201.

34. Qureshi J, Notta N, Salahuddin N, Zaman V, Khan J. An epidemic of dengue fever in Karachi-associated clinical manifestations. J Pak Medi Assoc. 1997: 47:178-81.

35. Idrees S, Ashfaq UA. A brief review on dengue molecular virology, diagnosis, treatment and prevalence in Pakistan. Genet Vaccines Ther. 2012; 10(1):6.

36. Ahmed S, Mohammad WW, Hamid F, Akhter A, Afzal RK, et al. The 2011 dengue haemorrhagic fever outbreak in Lahore-an account of clinical parameters and pattern of haemorrhagic complications. J Coll Physicians Surg Pak. 2013;23:463-7.

37. Ahmed S, Arif F, Yahya Y, Rehman A, Abbas K, et al. Dengue fever outbreak in Karachi 2006-a study of profile and outcome of children under 15 years of age. J Pak Med Assoc. 2008;58:4.

38. Jamil B, Hasan R, Zafar A, Bewley K, Chamberlain J, et al. Dengue virus serotype 3, Karachi, Pakistan. Emerg Infect Dis. 2007;13:182-4.

39. Khan E, Hasan R, Mehraj V, Nasir A, Siddiqui J, et al. Co-circulations of two genotypes of dengue virus in 2006 out-break of dengue hemorrhagic fever in Karachi, Pakistan. J Clin Virol. 2008:43:176-9.

40. Humayun MA, Waseem T, Jawa AA, Hashmi MS, Akram J. Multiple dengue serotypes and high frequency of dengue hemorrhagic fever at two tertiary care hospitals in Lahore during the 2008 dengue virus outbreak in Punjab, Pakistan. Inter J Infec Dis. 2010;14:e54-9.

41. Akram M, Fatima Z, Purdy MA, Sue A, Saleem S, et al. Introduction and evolution of dengue virus type 2 in Pakistan: a phylogeographic analysis. Virol J. 2015;12(1):1-11.

42. Ali A, Nasim Z, Rehman R, Ali FS, Zahir F, et al. Dengue virus serotype 2 and 3 causing high morbidity and mortality in Swat, Pakistan. Biohelikon Immu Dis. 2013;1:1-3.

43. Koo C, Nasir A, Hapuarachchi HC, Lee K-S, Hasan Z, et al. Evolution and heterogeneity of multiple serotypes of dengue virus in Pakistan, 2006-2011. Virol J. 2013;10(1):275.

44. Khaskheli A, Qazi N, Mahadev H, Ujan I. Pattern of dengue virus infection cases admitted in tertiary care hospital at Hyderabad, Sindh. JLUMHS. 2010:9:142

45. Teixeira MG, Siqueira JB Jr, Ferreira GL, Bricks L, Joint G. Epidemiological trends of denque disease in Brazil (2000-2010): a systematic literature search and analysis. PLoS Negl Trop Dis. 2013;7:e2520.

46. Halstead SB. Dengue in the Americas and Southeast Asia: do they differ? Revis Panam de Salud Pub. 2006;20:407-15.

47. Bhatty S, Shaikh NA, Fatima M, Sumbhuani AK. Acute acalculous cholecystitis in dengue fever. Headache. 2009;4:36.

48. Malik M. Dengue prevention, control and management in Proceedings of the WHO Collaborated International Conference, Lahore, Pakistan, 2012.

49. Hayes C, Baqar S, Ahmed T, Chowdhry M, Reisen W. West Nile virus in Pakistan. 1. Sero-epidemiological studies in Punjab Province. Trans R Soc Trop Med Hyg. 1982;76:431-6.

50. Raza FA, ur Rehman S, Khalid R, Ahmad J, Ashraf S, et al. Demographic and clinico-epidemiological features of dengue fever in Faisalabad, Pakistan. PLoS One. 2014:9:e89868.

51. Salahuddin N, Ali F, Ali M, Rashid F. Dengue fever outbreak in Karachi, 2005: a clinical experience. Infect Dis J. 2005;14:115-7.

52. Shamim M. Frequency, pattern and management of acute abdomen in denque fever in Karachi, Pakistan. Asian J Surg. 2010;33:107-13.

53. Zafar H, Bukhari KT, Lodhi GM. Global prevalence of dengue viral infection, its pathogenesis, diagnostic and preventive approaches. Asian J Agri Biol. 2013;1:38-42.

54. Criterion I. Seroprevalence of dengue viral infection in healthy population residing in rural areas of district Rawalpindi. Int J Path. 2010;8:13-5. 
55. Wasay M, Channa R, Jumani M, Zafar A. Changing patterns and outcome of denque infection; report from a tertiary care hospital in Pakistan. J Pak Med Assoc. 2008;58:488.

56. Sulehri MA, Hussain R, Gill NI. Dengue fever its diagnosis, treatment, prevention and control. Gomal J Med Sci. 2012;6:22-7.

57. Sherin A. Dengue fever: a major public health concern in Pakistan. Khy Med J. 2011;3:1-3.

58. Fatima Z, Idrees M, Bajwa MA, Tahir Z, Ullah O, Zia MQ, Hussain A, Akram M, Khubaib B, Afzal S, et al. Serotype and genotype analysis of dengue virus by sequencing followed by phylogenetic analysis using samples from three mini outbreaks-2007-2009 in Pakistan. BMC Microbiol. 2011;11(1):200.58.

59. Ali A, ur Rehman H, Nisar M, Rafique S, Ali S, et al. Seroepidemiology of dengue fever in Khyber Pakhtunkhawa, Pakistan. Int J Infec Dis. 2013;17: e518-23.

60. Almas A, Parkash O, Akhter J. Clinical factors associated with mortality in dengue infection at a tertiary care center. Southeast Asian J Trop Med Public Health. 2010;41:333-40.

61. Jahan F. Dengue fever (DF) in Pakistan. Asia Pac Fam Med. 2011;10(1)

62. Khan E, Siddiqui J, Shakoor S, Mehraj V, Jamil B, et al. Dengue outbreak in Karachi, Pakistan, 2006: experience at a tertiary care center. Trans Royal Soc Trop Med Hyg. 2007;101:1114-9.

63. Itrat A, Khan A, Javaid S, Kamal M, Khan H, et al. Knowledge, awareness and practices regarding dengue fever among the adult population of dengue hit cosmopolitan. PLoS One. 2008;3:e2620.

64. Khan E, Kisat M, Khan N, Nasir A, Ayub S, et al. Demographic and clinical features of dengue fever in Pakistan from 2003-2007: a retrospective crosssectional study. PLoS One. 2010;5:e12505.

65. Mahmood K, Jameel T, Aslam HF, Tahir M. Incidence of dengue haemorrhagic fever in local population of Lahore. Pakistan Biomedica. 2009; 25:93-6.

66. San Martin JL, Brathwaite O, Zambrano B, Solorzano JO, Bouckenooghe A, et al. The epidemiology of dengue in the Americas over the last three decades: a worrisome reality. Ameri J Trop Med Hyg. 2010;82:128-35.

67. Mahmood S, Nabeel H, Hafeez S, Zahra U, Nazeer H. Seroprevalence of dengue lgG antibodies among healthy adult population in Lahore, Pakistan. ISRN Trop Med. 2013:1-10.

68. Luqman M, Sattar T, Farid S, Warraich IA, Khan WA. Effects of dengue incidence on socio-economic status of Patient's family: a comparative analysis of Multan and Lahore City (Pakistan). J Econ Sustain Dev. 2013; 4:28-40.

69. Butt N, Abbassi A, Munir S, Ahmad SM, Sheikh QH. Haematological and biochemical indicators for the early diagnosis of dengue viral infection. J Coll Physicians Surg Pak. 2008;18:282-5.

70. Ali N, Nadeem A, Anwar M, Tariq W, Chotani RA. Dengue fever in malaria endemic areas. Journal of the College of Physicians and Surgeons-Pakistan. J Coll Physicians Surg Pak. 2006;16:340-2.

71. Khanani MR, Arif A, Dengue in Pakistan SR. Journey from a disease free to a hyper endemic nation. J Dow Univ Health Sci. 2011:5(3):81-4.

72. Bota R, Ahmed M, Jamali MS, Aziz A. Knowledge, attitude and perception regarding dengue fever among university students of interior Sindh. J Infec Pub Health. 2014;7:218-23.

73. Syed M, Saleem T, Syeda U-R, Habib M, Zahid R, et al. Knowledge, attitudes and practices regarding dengue fever among adults of high and low socioeconomic groups. J Pak Med Assoc. 2010;60:243.

74. Naeem-Ullah U, Akram W. Dengue knowledge, attitudes and practices in Multan, Pakistan: an urban area at the verge of dengue infestation. Pub Health. 2009;123:452-3.

75. Murray NEA, Quam MB, Wilder-Smith A. Epidemiology of dengue: past, present and future prospects. Clin Epidemiol. 2013;5:299.

76. Khan MA, Ellis EM, Tissera HA, Alvi MY, Rahman FF, et al. Emergence and diversification of dengue 2 cosmopolitan genotype in Pakistan, 2011. PLoS One. 2013;8:e56391.

77. Khan E, Hasan R, Mehraj J, Mahmood S. Genetic diversity of dengue virus and associated clinical severity during periodic epidemics in South East Asia. Current Topics Tropl Med. 2013;91:92-108.

78. Usman M, Jamal S, Tabassum S, Zafran M. Outcome of dengue fever in adults. J Gomal Med Sci. 2011;9(1):70-3.

79. Idrees M, Hussain W, Rehman HU, Tayyab GUN, Afzal S, et al. Dengue virus serotype 2 (DEN-2): the causative agent of 2011-dengue epidemic in Pakistan. Am J Biomed Sci. 2012;4:307-15.
80. Khalid B, Ghaffar A. Dengue transmission based on urban environmental gradients in different cities of Pakistan. Int J Biometeorol. 2014; https://doi org/10.1007/s00484-014-0840-6.

81. Suleman M, Faryal R, Alam MM, Khurshid A, Sharif S, Shaukat S, Angez M, et al. Outbreak of dengue virus type-3 in Malakand, Pakistan 2015; a laboratory perspective. Acta Trop. 2017;169:202-6.

82. Mukhtar M, Jeroen E, van der Hoek W, Felix PA, Konradsen F. Importance of waste stabilization ponds and wastewater irrigation in the generation of vector mosquitoes in Pakistan. J Med Entomol. 2006;43(5):996-1003.

\section{Ready to submit your research? Choose BMC and benefit from:}

- fast, convenient online submission

- thorough peer review by experienced researchers in your field

- rapid publication on acceptance

- support for research data, including large and complex data types

- gold Open Access which fosters wider collaboration and increased citations

- maximum visibility for your research: over $100 \mathrm{M}$ website views per year

At BMC, research is always in progress.

Learn more biomedcentral.com/submissions 